\title{
A New Method Based on TOPSIS and Response Surface Method for MCDM Problems with Interval Numbers
}

\author{
Peng Wang, ${ }^{1}$ Yang Li, ${ }^{1}$ Yong-Hu Wang, ${ }^{2}$ and Zhou-Quan Zhu' \\ ${ }^{1}$ School of Marine Science and Technology, Northwestern Polytechnical University, Xian 710072, China \\ ${ }^{2}$ Flight Technology College, Civil Aviation Flight University of China, Guanghan, Sichuan 618307, China \\ Correspondence should be addressed to Peng Wang; wangpeng305@nwpu.edu.cn
}

Received 8 December 2014; Revised 30 March 2015; Accepted 9 April 2015

Academic Editor: Marek Lefik

Copyright (C) 2015 Peng Wang et al. This is an open access article distributed under the Creative Commons Attribution License, which permits unrestricted use, distribution, and reproduction in any medium, provided the original work is properly cited.

As the preference of design maker (DM) is always ambiguous, we have to face many multiple criteria decision-making (MCDM) problems with interval numbers in our daily life. Though there have been some methods applied to solve this sort of problem, it is always complex to comprehend and sometimes difficult to implement. The calculation processes are always ineffective when a new alternative is added or removed. In view of the weakness like this, this paper presents a new method based on TOPSIS and response surface method (RSM) for MCDM problems with interval numbers, RSM-TOPSIS-IN for short. The key point of this approach is the application of deviation degree matrix, which ensures that the DM can get a simple response surface (RS) model to rank the alternatives. In order to demonstrate the feasibility and effectiveness of the proposed method, three illustrative MCMD problems with interval numbers are analysed, including (a) selection of investment program, (b) selection of a right partner, and (c) assessment of road transport technologies. The contrast of ranking results shows that the RSM-TOPSIS-IN method is in good agreement with those derived by earlier researchers, indicating it is suitable to solve MCDM problems with interval numbers.

\section{Introduction}

MCDM, which is short for multiple criteria decision making, is a problem about how to find the best option from all of the feasible alternatives on the basis of two or more attributes. In order to deal with this sort of problem, many methods have been developed, for instance, simple additive weighting (SAW) [1], order preference by similarity to ideal solution (TOPSIS) method [2], analytic hierarchy process (AHP) [3], grey relational analysis (GRA) [4], and multiobjective optimization on the basis of ratio analysis (MOORA) method [5]. All these approaches have been applied in solving a variety of MCDM problems, including plant layout design problem [6], optimization [7], material selection [8], and forestry [9]. Among all the related methods, TOPSIS has gained popularity in the field of MCDM because of its simplicity and practicality [10-13].

However, since human judgments including preferences are often vague and cannot be estimated with an exact numerical value, therefor these data may be expressed by a number of ways, such as bounded data, ordinal data, interval data, and fuzzy data [14]. Since most criteria of these problems have interdependent and interactive features, they cannot be evaluated by conventional measures method. Bellman \& Zadeh [15] are the first to study on the decision-making problem under a fuzzy environment-watershed. They heralded the initiation of fuzzy MCDM and this analysis method is then widely used to deal with decision-making problems involving multiple criteria evaluation/selection of alternatives. In many practical MCDM, fuzzy MCDM approaches using interval numbers instead of exact values now have been introduced and illustrated in many literatures. For example, a multicriteria group decision making for evaluation of supplier using intuitionistic fuzzy TOPSIS is presented by Boran et al. [16]. Lee et al. [17] constructed an approach based on the fuzzy analytic hierarchy process (FAHP) and balanced scorecard (BSC) to evaluate an IT department. An example whose attributes weights and ratings are expressed by interval numbers is successfully solved through the GRA-based TOPSIS decision-making approach proposed by Peng and Wang [18], 
and also there is a good survey done by Chen et al. [19] who make distinctions between fuzzy ranking methods and fuzzy multiple attribute decision-making methods.

Compared with the traditional MCDM models, the fuzzy versions of MCDM applications are very complex to comprehend and sometimes difficult to implement [20]. On one hand, while the MCDM model consisted of interval numbers, too much mathematical calculation leads to more computation time, making it impracticable and ineffective to the decision makers (DMs) without a strong capability in mathematics. At the same time, the range of intervals may become more and more wide along with the calculation, which will be more difficult for the DMs to make the final choice. On the other hand, if the decision alternatives are changed, or an alternative is added or removed, the DMs have to analyse the problem from the beginning again. It is really a waste of time. So, how to find some simple ways to deal with the MCDM problems with interval numbers becomes an important study topic for the researchers. The one which involves a unique expression to fulfill differing task requirements may be an ideal choice.

In this paper, we present a new method based on TOPSIS and response surface method (RSM) for MCDM problems with interval numbers (RSM-TOPSIS-IN). In experimental design, the best and worst intervals of each attribute are combined to represent all the possibilities of alternatives approximately. With the application of deviation degree matrix, the experimental data can be used to get a response surface (RS) model, helping the DMs to acquire the ranking results through the established equation simply. What is more, if some new alternatives are considered later, we can only use the established RS model to get the ranking results easily, reducing both time and effort a lot. Three practical MCDM problems that consisted of interval numbers will be solved by the RSM-TOPSIS-IN method we proposed. The compared results will show that it can help the DMs to get the most appropriate alternative in complex MCDM problems, using both less time and less calculation.

The reminder of this paper is organized as follows. Section 2 focuses on presenting a brief review of related methods, involving interval numbers, TOPSIS method, experimental design, and response surface method. Then, the detailed processes of the RSM-TOPSIS-IN method are stated in Section 3. In Section 4, two more illustrative examples are described to demonstrate the capabilities of the proposed method. Finally, conclusions and future research areas are discussed in Section 5.

\section{Backgrounds}

2.1. Interval Numbers. In the real world, the decision-making problems are always very vague and uncertain, which may be expressed by a variety of ways, such as bounded number, ordinal number, interval number, and fuzzy number. Considering these problems are not like the conventional issues with exact values, they cannot be evaluated by common methods. Bellman \& Zadeh [15] are the first ones who studied the decision-making problem under a fuzzy environmentwatershed and they heralded the initiation of fuzzy MCDM.
Whereafter, this analysis method is widely used to deal with decision-making problems involving multiple criteria evaluation of alternatives.

Among all the fuzzy MCDM problems, interval numbers and fuzzy numbers are used the most to construct the decision matrix. Interval numbers are a set of real numbers with the property that any number that lies between two numbers is also included in the set [21]. Fuzzy numbers are expressed by a fuzzy subset of real numbers, representing the expansion of the idea of the confidence interval [22], for the fuzzy numbers are developed based on the interval numbers. In this paper, we only talk about the special part of fuzzy MCDM problems, which are the problems with interval numbers actually. Though there have been some articles aiming at the study on interval numbers in recent years, finding a more complete and robust methodology is still needed. It is worth mentioning that transforming the uncertain problem to a deterministic problem seems a good way for this sort of problems [23].

In this section, some basic definitions [24] used to solve the interval numbers will be introduced briefly, helping us to know more about the interval numbers. Suppose $a=$ $\left[a^{-}, a^{+}\right]=\left\{x \mid 0 \leq a^{-} \leq x \leq a^{+}\right\}, b=\left[b^{-}, b^{+}\right]=\{x \mid$ $\left.0 \leq b^{-} \leq x \leq b^{+}\right\}$are two positive interval numbers, and then one can find the following.

Definition 1. Consider

$$
a+b=\left[a^{-}+b^{-}, a^{+}+b^{+}\right] .
$$

Definition 2. Consider

$$
a-b=\left[a^{-}-b^{+}, a^{+}-b^{-}\right] .
$$

Definition 3. Consider

$$
\begin{gathered}
a \times b=\left[\min \left(a^{-} b^{-}, a^{-} b^{+}, a^{+} b^{-}, a^{+} b^{+}\right),\right. \\
\left.\max \left(a^{-} b^{-}, a^{-} b^{+}, a^{+} b^{-}, a^{+} b^{+}\right)\right] .
\end{gathered}
$$

Definition 4. Consider

$$
\frac{a}{b}=\left[a^{-}, a^{+}\right] \cdot\left[\frac{1}{b^{+}}, \frac{1}{b^{-}}\right] .
$$

Definition 5. Consider

$$
D(a, b)=\frac{\sqrt{2}}{2} \sqrt{\left(a^{-}-b^{-}\right)^{2}+\left(a^{+}-b^{+}\right)^{2}} .
$$

It is worth mentioning that the application of distance definition is the key point of the proposed method in this paper. Actually, the distance definition is the fifth definition given above. In different articles, the main idea of distance definition is the same, but the expressions are always not like each other. Particularly, separations measured by Hamming distance and Euclidean distance are discussed in paper [25].

In order to get the deviation degree matrix, we must make some change to the decision plan. Suppose $X$ is the decision matrix of a MCDM problem with interval numbers, $A_{1}, A_{2}, \ldots, A_{n}$, included, representing $n$ alternatives that 
need to be evaluated or $n$ decision plans to be studied. $A_{i}=\left(\left[x_{i 1}{ }^{-}, x_{i 1}{ }^{+}\right],\left[x_{i 2}{ }^{-}, x_{i 2}{ }^{+}\right], \ldots,\left[x_{i m}{ }^{-}, x_{i m}{ }^{+}\right]\right)$is the $i$ th alternative and $x_{i j}=\left[x_{i 1}, x_{i 1}{ }^{+}\right]$is the $j$ th attribute of alternative $A_{i}$. According to all alternatives in $X$, an ideal alternative $I=\left(\left[B_{1}, B_{1}\right],\left[B_{2}, B_{2}\right], \ldots,\left[B_{m}, B_{m}\right]\right)$ will be decided. $\left[B_{j}, B_{j}\right]$ has the same lower and upper values, which is the best value that the $j$ th attribute can reach. Then, by calculating the distance between each attribute and its ideal interval that can be reached, the decision matrix that consisted of interval attributes will be transformed to a normal matrix with true values, just as shown below, where $d_{i j}=(\sqrt{2} / 2) \sqrt{\left(x_{i j}{ }^{-}-B_{j}^{-}\right)^{2}+\left(x_{i j}{ }^{+}-B_{j}^{+}\right)^{2}}$ based on (5)

$$
\begin{aligned}
X & =\left[\begin{array}{cccc}
{\left[x_{11}^{-}, x_{11}^{+}\right]} & {\left[x_{12}^{-}, x_{12}^{+}\right]} & \cdots & {\left[x_{1 m}^{+}, x_{1 m}^{-}\right]} \\
{\left[x_{21}^{-}, x_{21}^{+}\right]} & {\left[x_{22}^{-}, x_{22}^{+}\right]} & \cdots & {\left[x_{2 m}^{-}, x_{2 m}^{+}\right]} \\
\vdots & \vdots & \vdots \\
{\left[x_{n 1}^{-}, x_{n 1}^{+}\right]} & {\left[x_{n 2}^{-}, x_{n 2}^{+}\right]} & \cdots & {\left[x_{n m}^{-}, x_{n m}^{+}\right]}
\end{array}\right] \rightarrow D \\
= & {\left[\begin{array}{cccc}
d_{11} & d_{12} & \cdots & d_{1 m} \\
d_{21} & d_{22} & \cdots & d_{2 m} \\
\vdots & \vdots & & \vdots \\
d_{n 1} & d_{n 2} & \cdots & d_{n m}
\end{array}\right] . }
\end{aligned}
$$

2.2. TOPSIS Method. TOPSIS method, a widely used approach for MCDM problems, is developed by Hwang and Yoon in 1981 [26] and further developed by Yoon [27] and Hwang et al. [28]. The basic principle of this method is that the best decision should be the closest to the ideal solution and farthest from the nonideal solution [29]. It assumes that each attribute is monotonically increasing or decreasing, making it easy to locate the best and worst selection visually. Normalization is usually required as the parameters or criteria are often of incongruous dimensions in multicriteria problems [30]. Euclidean distance, which is given by the Pythagorean formula [31], is applied to measure the alternatives. Considering the Euclidian Distance Metric may produce many symmetric solutions, the weights, which represent the importance of each criterion, are added to its criterion after the process of normalization. The final rank is reached by comparing the Euclidean distances of all alternatives.

There exist some disadvantages in the traditional TOPSIS method, such that (1) the Euclidean distance algorithm it uses in principle does not consider the correlation of attributes and (2) generally the weight coefficients acquired by expert investigation method or AHP method both have subjectivity. It is also considered as a good choice for MCDM problems because of the following reasons. (1) It is relatively easy and fast. (2) It is useful for qualitative and quantitative data. (3) The output can be a preferential ranking using both negative and positive criteria [32]. Because of these advantages, TOPSIS has been widely used and developed to deal with MCDM problems in fuzzy environment [14, 33]. In view of its simpleness and wide application, we choose
TOPSIS to solve the MCDM problems with interval numbers also.

Suppose that MCDM problem is composed of $m$ alternatives $\left(A_{1}, A_{2}, \ldots, A_{m}\right)$ and $n$ criteria $\left(C_{1}, C_{2}, \ldots, C_{n}\right)$. Matrix $X=\left[x_{i j}\right]_{m \times n}$ shows all values assigned to the alternatives concerning each criterion. The related weight of each criterion has been denoted by $W=\left[w_{1}, w_{2}, \ldots, w_{n}\right]$ with the condition $\sum_{j=1}^{n} w_{j}=1$.

The detailed steps of TOPSIS [34] are carried out as follows.

Step 1. Normalize the decision matrix:

$$
r_{i j}=\frac{x_{i j}}{\sqrt{\sum_{k=1}^{m} x_{k j}^{2}}}, \quad i=1, \ldots, m ; j=1, \ldots, n,
$$

where $r_{i j}$ denotes the normalized value of $j$ th criteria for the $i$ th alternative $A_{i}$.

Step 2. Calculate the weighted normalized decision matrix,

$$
v_{i j}=w_{j} r_{i j}, \quad i=1, \ldots, m ; j=1, \ldots, n,
$$

where $w_{j}$ is the weight of the $j$ th criteria or attribute.

Step 3. Determine the positive ideal and negative ideal solutions:

$$
\begin{aligned}
& A^{+}=\left\{v_{1}^{+}, \ldots, v_{n}^{+}\right\}, \\
& A^{-}=\left\{v_{1}^{-}, \ldots, v_{n}^{-}\right\},
\end{aligned}
$$

where $A^{+}$denotes the positive ideal solution and $A^{-}$denotes the negative ideal solution. If the $j$ th criterion is a beneficial criterion, $v_{j}^{+}=\max \left\{v_{i j}, i=1, \ldots, m\right\}$ and $v_{j}^{-}=\min \left\{v_{i j}, i=\right.$ $1, \ldots, m\}$. On the contrary, if the $j$ th criterion is cost criterion, $v_{j}{ }^{+}=\min \left\{v_{i j}, i=1, \ldots, m\right\}$ and $v_{j}{ }^{-}=\max \left\{v_{i j}, i=1, \ldots, m\right\}$.

Step 4. Calculate the distances of each alternative from the positive ideal solution and the negative ideal solution:

$$
\begin{aligned}
& S_{i}^{+}=\sqrt{\sum_{j=1}^{n}\left(v_{i j}-v_{j}^{+}\right)^{2}}, \quad i=1, \ldots, m, \\
& S_{i}^{-}=\sqrt{\sum_{j=1}^{n}\left(v_{i j}-v_{j}^{-}\right)^{2}}, \quad i=1, \ldots, m,
\end{aligned}
$$

where $S_{i}^{+}$denotes the distance between the $i$ th alternative and the positive ideal solution and $S_{i}^{-}$denotes the distance between the $i$ th alternative and the negative ideal solution.

Step 5. Calculate the relative closeness to the ideal solution:

$$
R_{i}=\frac{S_{i}^{-}}{S_{i}^{+}+S_{i}^{-}}
$$

2.3. Experimental Design and Response Surface Method. Experimental design (also called design of experiment, DoE 
for short) is a statistical method used to determine the individual and interactive effects of many factors simultaneously on the system response [35]. It not only provides a full insight of the interaction between design elements, but also helps turning any standard design into a robust one. There are some key terms in DoE. Experimental domain is the experimental field defined by the minimum and maximum limits of the experimental variables. Factors are experimental variables that need to be studied and changed independently with each other. Levels are different values of each factor at which the experiments must be carried out. Response is the value of results measured from experiments [36].

It is important to choose an appropriate DoE method in the experimental design application. Though full factorial design, orthogonal array technique, Latin hypercube design, and optimal Latin hypercube design are the four active ones, the simplest and most common one is the factorial design that uses two levels, $n$ factors, that is, $2 n$ factorial design. It can reduce the number of experimental conditions. But due to its inability to distinguish between linear and higher order effects, the disadvantages exist at the same time. So, it is judicious to decide the number of levels in a factorial design experiment.

After the indispensable procedure mentioned above, the RSM can be applied to solve the problem further. In addition to analyzing the effects of each factor, RSM can also generate a mathematical model. The model collecting mathematical and statistical techniques is based on the fit of a polynomial equation to the experimental data. The concept of a response surface involves a dependent variable $f$ called the response variable and several independent variables $x_{1}, x_{2}, \ldots, x_{n}$ [37].

The relationship between the response surface and the experimental variables is given in the following equation:

$$
f=\beta_{0}+\sum_{i=1}^{n} \beta_{i} x_{i}+\sum_{i=1}^{n} \sum_{j=1}^{n} \beta_{i j} x_{i} x_{j}+\cdots+\varepsilon \quad i<j,
$$

where $n$ is the number of experimental variables, $\beta$ are the regression coefficients, and $\varepsilon$ is the statistical error, which represents other sources of variability [38].

In this paper, we pick out the best and worst interval of each attribute to do the $2 n$ factorial design. After transforming all interval numbers to real values, the data of DoE will be combined with TOPSIS method. Later, we can use the data set they created to generate a RS model. It will help the DMs to evaluate all the alternatives simply and quickly.

\section{Illustration of the Proposed Method}

3.1. Framework of the RSM-TOPSIS-IN Method. There are four basic stages in the RSM-TOPSIS-IN method. In the first stage, the DMs get the decision matrix of MCDM problem. In stage 2, the DMs have to acquire the deviation degree matrix of experimental design. First, input attributes and their levels are determined according to the decision matrix. Then, the experimental design of intervals is carried out. With the aforementioned concept presented in Section 2.1, the deviation degree matrix of experimental design is realized finally. The third stage of the proposed methodology is

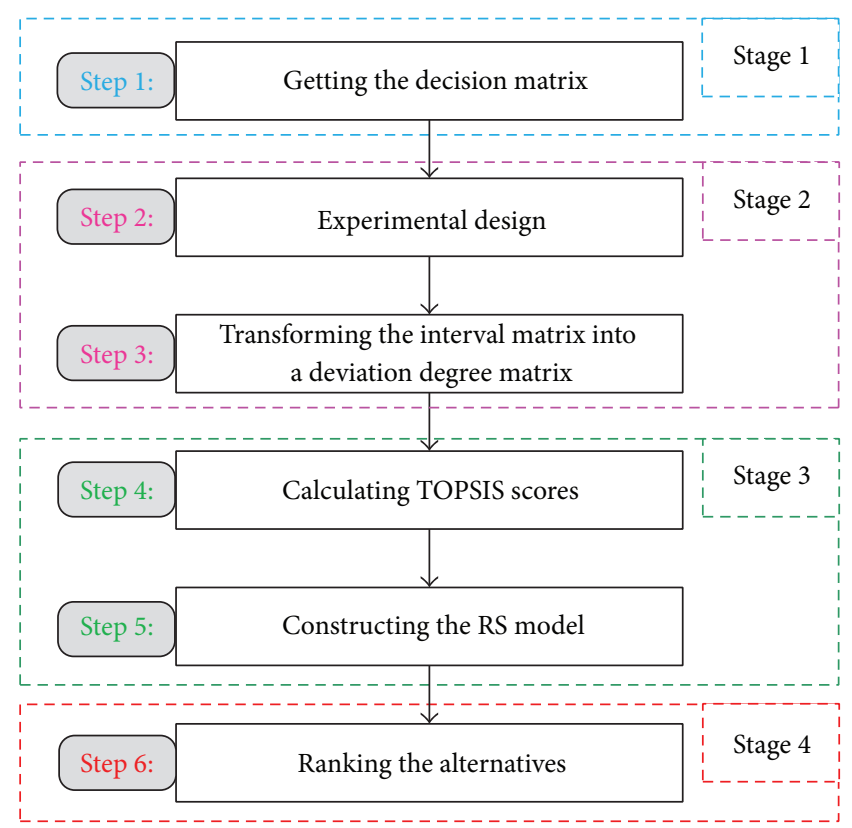

FIGURE 1: Steps of the RSM-TOPSIS-IN method.

constructing the RS model based on the TOPSIS scores, which are calculated by the TOPSIS method introduced in Section 2.2. In the last stage, the DMs are able to evaluate alternatives and determine the final ranking results, using the established RS model simply. Flow diagram of the proposed approach is illustrated in Figure 1.

In order to introduce the detailed processes of the RSMTOPSIS-IN method, a simple but persuasive problem about what investment to choose is demonstrated in the following section. Design Expert and MATLAB, two essential software programs we use, make the proposed method feasible. The design of experiment and the establishment of RS model are realized under the help of Design Expert. MATLAB undertakes all the calculations during the application.

3.2. Detailed Steps of the RSM-TOPSIS-IN Method. In this section, we present a practical example to illustrate the detailed processes of the RSM-TOPSIS-IN method. It is about how to select a proper investment program [39]. A company is going to develop a new product and it has formulated five investment alternatives to choose. Each alternative consists of investment (IN), profit of expectation (EP), profit of risk (RP), and the cost of risk (RC), whose attributes are all expressed by interval numbers instead of real values. Among the four attributes, EP and RP are two beneficial attributes while IN and RC are nonbeneficial ones. Beneficial attribute means higher value is desirable, whereas nonbeneficial attribute prefers lower value. Next, various steps will be carried out to show the details of the RSM-TOPSIS-IN application.

Step 1 (get the decision matrix). According to the specific decision matrix shown in Table 1 , IN with minimum interval $[5,6]$ and maximum interval $[10,11]$, EP with minimum interval $[3,5]$ and maximum interval $[6,7]$, RP with minimum interval $[3,4]$ and maximum interval $[5,7]$, and $\mathrm{RC}$ 
TABLE 1: Decision matrix for investment program.

\begin{tabular}{lcccc}
\hline Alternatives & IN & EP & RP & RC \\
\hline$A_{1}$ & {$[5,7]$} & {$[4,5]$} & {$[4,6]$} & {$[0.4,0.6]$} \\
$A_{2}$ & {$[10,11]$} & {$[6,7]$} & {$[5,6]$} & {$[1.5,2.0]$} \\
$A_{3}$ & {$[5,6]$} & {$[4,5]$} & {$[3,4]$} & {$[0.4,0.7]$} \\
$A_{4}$ & {$[9,11]$} & {$[5,6]$} & {$[5,7]$} & {$[1.3,1.5]$} \\
$A_{5}$ & {$[6,8]$} & {$[3,5]$} & {$[3,4]$} & {$[0.8,1.0]$} \\
\hline Min/max & Min & Max & Max & Min \\
\hline Best & {$[5,6]$} & {$[6,7]$} & {$[5,7]$} & {$[0.4,0.6]$} \\
Worst & {$[10,11]$} & {$[3,5]$} & {$[3,4]$} & {$[1.5,2.0]$} \\
\hline
\end{tabular}

with minimum interval $[0.4,0.6]$ and maximum interval $[1.5,2.0]$ are determined as factor levels affecting the investment program selection. "Max" means the attribute is beneficial and "Min" represents that the attribute is nonbeneficial. For five different alternatives, $A_{1}$ has the lowest cost of risk, the advantage of $A_{2}$ is the high profit of expectation, the investment of $A_{3}$ is in a relatively higher interval, profit of risk provided by $A_{4}$ is the most attractive one, and though $A_{5}$ does not have a best attribution, some of them are better than others. So, it is really a hard work to make a decision.

Step 2 (experimental design). As shown in Table 1, it is easy to pick out the best interval and the worst interval of each attribute. Because the impacts of each factor are different on ranking results, we utilize the experimental design to assess their influence. In this example, a two-level factorial design was used to create a data set with all combination of the best interval and the worst interval of each attribute. Generally, the orthogonal arrays with two-level factors are expressed by $L_{A}\left(2^{B}\right)$, where $A=2^{N}$ is the number of experiments, $N$ is a positive integer which is more than $1, B$ denotes the number of dependent factors, and 2 means the experiment is taken as a two-level factorial design. The letter " $L$ " comes from Latin, which has been associated with Latin square designs from the outset using orthogonal arrays for experimental design. In the orthogonal table based on two levels, four factors are given in Table 2 .

Step 3 (transform the orthogonal table to a deviation degree matrix). For it is not easy to handle a fuzzy MCDM problem with interval numbers, a creative method which turns the interval number to a real value is developed. It calculates the distance between two intervals of the same attribute so the orthogonal table can be transformed to a deviation degree matrix.

First, determine an ideal alternative that consists of the intervals with the same upper and lower bounds based on the decision matrix. Because 5, 7, 7, 0.4 are the best limits that can be reached to five alternatives, $([5,5],[7,7],[7,7],[0.4,0.4])$ is chosen as the ideal alternative in this issue. Then, calculate the distance between each attribute shown in Table 2 and the ideal alternative according to (5). The deviation degree matrix of experimental design is shown in Table 3.

Step 4 (calculate the TOPSIS scores). In this procedure, the TOPSIS scores of all the alternatives in DoE should be
TABLE 2: Experimental design results of attribute factors.

\begin{tabular}{lcccc}
\hline \multirow{2}{*}{ Exp. number } & \multicolumn{4}{c}{ Factor levels } \\
& IN & EP & RP & RC \\
\hline 1 & {$[5,6]$} & {$[6,7]$} & {$[5,7]$} & {$[0.4,0.6]$} \\
2 & {$[5,6]$} & {$[6,7]$} & {$[5,7]$} & {$[1.5,2.0]$} \\
3 & {$[5,6]$} & {$[6,7]$} & {$[3,4]$} & {$[0.4,0.6]$} \\
4 & {$[5,6]$} & {$[6,7]$} & {$[3,4]$} & {$[1.5,2.0]$} \\
5 & {$[5,6]$} & {$[3,5]$} & {$[5,7]$} & {$[0.4,0.6]$} \\
6 & {$[5,6]$} & {$[3,5]$} & {$[5,7]$} & {$[1.5,2.0]$} \\
7 & {$[5,6]$} & {$[3,5]$} & {$[3,4]$} & {$[0.4,0.6]$} \\
8 & {$[5,6]$} & {$[3,5]$} & {$[3,4]$} & {$[1.5,2.0]$} \\
9 & {$[10,11]$} & {$[6,7]$} & {$[5,7]$} & {$[0.4,0.6]$} \\
10 & {$[10,11]$} & {$[6,7]$} & {$[5,7]$} & {$[1.5,2.0]$} \\
11 & {$[10,11]$} & {$[6,7]$} & {$[3,4]$} & {$[0.4,0.6]$} \\
12 & {$[10,11]$} & {$[6,7]$} & {$[3,4]$} & {$[1.5,2.0]$} \\
13 & {$[10,11]$} & {$[3,5]$} & {$[5,7]$} & {$[0.4,0.6]$} \\
14 & {$[10,11]$} & {$[3,5]$} & {$[5,7]$} & {$[1.5,2.0]$} \\
15 & {$[10,11]$} & {$[3,5]$} & {$[3,4]$} & {$[0.4,0.6]$} \\
16 & {$[10,11]$} & {$[3,5]$} & {$[3,4]$} & {$[1.5,2.0]$} \\
\hline
\end{tabular}

calculated. As introduced in Section 2.2, the TOPSIS method is applied to get the experimental results with two weight sets. $\omega_{1}=(0.28,0.17,0.23,0.32)$ is defined by article [39] and $\omega_{2}=$ $(0.15,0.20,0.20,0.45)$ comes from article [40]. The TOPSIS scores of experimental design are presented in Table 3 also.

Step 5 (construct the RS model). In addition to the main effects of four factors, interactions between two factors are also included in the RS model, as shown in the following equation:

$$
R=\beta_{0}+\sum_{i=1}^{4} \beta_{i} x_{i}+\sum_{i=1}^{4} \sum_{j=1}^{4} \beta_{i j} x_{i} x_{j}+\varepsilon
$$

where $R$ is the relevant $R_{i}$ of sixteen alternatives. $\beta_{0}$ is the intercept coefficient, $\beta_{i}$ means the first-order effect of factor $i$, and $\beta_{i j}$ shows the two-factor interaction between factors $i$ and $j$ when $i \neq j$, just as introduced before.

In order to check out whether the established RS model can describe the real relationship or not, it must be analyzed by the analysis of variance (ANOVA) procedure. The ANOVA results can be achieved with the help of the software called Design Expert. It gives a summary of the main effects and interaction effects of factors, which helps us to get the final RS model fitting to the experimental data. In the ANOVA table, values of " $p$ value" less than 0.0500 indicate model terms are significant. If the value of "Pred $R$-Squared" is in reasonable agreement with the value of "Adj $R$-Squared," it will prove that this model can be used to navigate the design space.

As shown in Table 4, for the RS model with $\omega_{1}$, IN, EP, and RC are three significant model terms. The value of "Pred $R$ Squared" is 0.7988 and the value of "Adj $R$-Squared" is 0.8825 , indicating an adequate signal that this model can be used to get the final ranking results. The same analysis is also done for the RS model with $\omega_{2}$. In this model, four factors are all available and the value of "Pred $R$-Squared" is in good 
TABle 3: The deviation degree matrix and TOPSIS scores of experimental design.

\begin{tabular}{|c|c|c|c|c|c|c|}
\hline \multirow{2}{*}{ Exp. number } & \multicolumn{4}{|c|}{ Factor levels } & \multicolumn{2}{|c|}{ TOPSIS scores } \\
\hline & IN & $\mathrm{EP}$ & $\mathrm{RP}$ & $\mathrm{RC}$ & $\omega_{1}$ & $\omega_{2}$ \\
\hline 1 & 0.7071 & 0.7071 & 1.4142 & 0.1414 & 0 & 0 \\
\hline 2 & 0.7071 & 0.7071 & 1.4142 & 1.3730 & 0.4912 & 0.6446 \\
\hline 3 & 0.7071 & 0.7071 & 3.5355 & 0.1414 & 0.2445 & 0.2003 \\
\hline 4 & 0.7071 & 0.7071 & 3.5355 & 1.3730 & 0.5401 & 0.6854 \\
\hline 5 & 0.7071 & 3.1623 & 1.4142 & 0.1414 & 0.2166 & 0.2287 \\
\hline 6 & 0.7071 & 3.1623 & 1.4142 & 1.3730 & 0.5277 & 0.7204 \\
\hline 7 & 0.7071 & 3.1623 & 3.5355 & 0.1414 & 0.3083 & 0.2874 \\
\hline 8 & 0.7071 & 3.1623 & 3.5355 & 1.3730 & 0.5781 & 0.7572 \\
\hline 9 & 0.7071 & 0.7071 & 1.4142 & 0.1414 & 0.4170 & 0.2291 \\
\hline 10 & 5.5227 & 0.7071 & 1.4142 & 1.3730 & 0.6881 & 0.7107 \\
\hline 11 & 5.5227 & 0.7071 & 3.5355 & 0.1414 & 0.4665 & 0.2883 \\
\hline 12 & 5.5227 & 0.7071 & 3.5355 & 1.3730 & 0.7808 & 0.7695 \\
\hline 13 & 5.5227 & 3.1623 & 1.4142 & 0.1414 & 0.4543 & 0.3062 \\
\hline 14 & 5.5227 & 3.1623 & 1.4142 & 1.3730 & 0.7525 & 0.7979 \\
\hline 15 & 5.5227 & 3.1623 & 3.5355 & 0.1414 & 0.5021 & 0.3487 \\
\hline 16 & 5.5227 & 3.1623 & 3.5355 & 1.3730 & 0.9818 & 0.9781 \\
\hline
\end{tabular}

TABLE 4: The ANOVA for two RS models.

\begin{tabular}{|c|c|c|c|c|c|}
\hline \multicolumn{3}{|c|}{ RS model with $\omega_{1}$} & \multicolumn{3}{|c|}{ RS model with $\omega_{2}$} \\
\hline Source & Coefficient & $p$ value & Source & Coefficient & $p$ value \\
\hline Intercept & -0.10875 & 0.0000 & Intercept & -0.12387 & 0.0000 \\
\hline IN & +3.22986 & 0.0013 & IN & +2.62822 & 0.0175 \\
\hline $\mathrm{EP}$ & +2.45232 & 0.0886 & EP & +2.66299 & 0.0209 \\
\hline $\mathbf{R P}$ & +2.54492 & 0.0482 & $\mathbf{R P}$ & +2.50448 & 0.0466 \\
\hline RC & +3.45764 & 0.0004 & RC & +3.74815 & $<0.0001$ \\
\hline $\mathrm{IN} * \mathrm{EP}$ & -1.22932 & 0.9619 & $\mathrm{IN} * \mathrm{EP}$ & -1.42959 & 0.9653 \\
\hline $\mathrm{IN} * \mathrm{RC}$ & -0.13025 & 0.9896 & $\mathrm{IN} * \mathrm{RC}$ & +0.41041 & 0.9693 \\
\hline $\mathrm{EP} * \mathrm{RP}$ & -2.29479 & 0.9624 & $\mathrm{EP} * \mathrm{RP}$ & -3.15194 & 0.9344 \\
\hline $\mathrm{EP} * \mathrm{RC}$ & -0.84065 & 0.9693 & $\mathrm{EP} * \mathrm{RC}$ & -1.06550 & 0.9201 \\
\hline $\mathrm{RP} * \mathrm{RC}$ & -0.67275 & 0.9716 & $\mathrm{RP} * \mathrm{RC}$ & -1.16626 & 0.9252 \\
\hline Adj $R$-Squared & \multicolumn{2}{|c|}{0.8825} & Adj $R$-Squared & \multicolumn{2}{|c|}{0.9823} \\
\hline Pred $R$-Squared & \multicolumn{2}{|c|}{0.7988} & Pred $R$-Squared & \multicolumn{2}{|c|}{0.9469} \\
\hline
\end{tabular}

agreement with the value of "Adj $R$-Squared." Based on the ANOVA results, $R_{1}$ and $R_{2}$ are established according to $\omega_{1}$ and $\omega_{2}$, respectively:

$$
\begin{aligned}
R_{1}= & -0.10875+3.22986 * \mathrm{IN}+2.54492 * \mathrm{RP} \\
& +3.45764 * \mathrm{RC}, \\
R_{2}= & -0.12387+2.62822 * \mathrm{IN}+2.66299 * \mathrm{EP} \\
& +2.50448 * \mathrm{RP}+3.74815 * \mathrm{RC} .
\end{aligned}
$$

Step 6 (rank the alternatives). After two RS models have been established, we can simply use (14) and (15) to get the ranking scores of each alternative. The deviation degree matrix of decision matrix is realized by repeating the steps of $1,3,4$, and 5 introduced above.

The ranking results of the RSM-TOPSIS-IN method are then compared with the ones obtained from two methods brought up by the same author but in different articles [39, 40], respectively. The results shown in Table 5 provide the information that the ranking results are exactly the same as the two other existing methods, which lead to the conclusion that the RSM-TOPSIS-IN method could be used to determine the final choice of investment program.

When applying the proposed method, the DMs make the problem a common case and easy to solve, by turning the decision matrix with interval numbers to a deviation degree matrix with exact values. For the calculation between two intervals costs is twice the time of the calculation between 
TABLE 5: The ranking results with two weight sets.

\begin{tabular}{lcccccc}
\hline \multirow{2}{*}{ Alternatives } & \multicolumn{3}{c}{ Ranking results with $\omega_{1}$} & \multicolumn{3}{c}{ Ranking results with $\omega_{2}$} \\
& Scores & RSM-TOPSIS-IN & Zhu and Chen [39] & Scores & RSM-TOPSIS-IN & Zhu [40] \\
\hline$A_{1}$ & 0.1262 & 1 & 1 & 0.2059 & 1 & 1 \\
$A_{2}$ & 0.7055 & 5 & 5 & 0.7618 & 5 & 2 \\
$A_{3}$ & 0.1728 & 2 & 2 & 0.2772 & 4 \\
$A_{4}$ & 0.5598 & 4 & 4 & 0.6170 & 4 \\
$A_{5}$ & 0.3510 & 3 & 3 & 0.4868 & 3 \\
\hline
\end{tabular}

TABLE 6: The performance characteristics of suppliers.

\begin{tabular}{|c|c|c|c|c|}
\hline Suppliers & Delivery lead time (A) & Product price (B) & Product quality (C) & Assortment flexibility (D) \\
\hline$S_{1}$ & {$[0.89,0.93]$} & {$[233,239]$} & {$[16,20]$} & {$[0.94,0.98]$} \\
\hline$S_{2}$ & {$[0.96,1.00]$} & {$[240,246]$} & {$[23,27]$} & {$[0.89,0.93]$} \\
\hline$S_{3}$ & {$[0.90,0.94]$} & {$[197,203]$} & {$[19,23]$} & {$[0.90,0.94]$} \\
\hline$S_{4}$ & {$[0.95,0.99]$} & {$[225,231]$} & {$[21,25]$} & {$[0.92,0.96]$} \\
\hline$S_{5}$ & {$[0.93,0.97]$} & {$[212,218]$} & {$[18,22]$} & {$[0.95,0.99]$} \\
\hline $\mathrm{Min} / \max$ & $\operatorname{Max}$ & Min & Min & Max \\
\hline Best & {$[0.96,1.00]$} & {$[197,203]$} & {$[16,20]$} & {$[0.95,0.99]$} \\
\hline Worst & {$[0.89,0.93]$} & {$[240,246]$} & {$[23,27]$} & {$[0.89,0.93]$} \\
\hline
\end{tabular}

TABLE 7: The ANOVA for RS model.

\begin{tabular}{|c|c|c|c|c|c|}
\hline Source & Coefficient & $p$ value & Source & Coefficient & $p$ value \\
\hline Intercept & -0.16128 & 0.0000 & $\mathrm{AC}$ & $8.36 E-16$ & 1.0000 \\
\hline A & 3.37115 & 0.0011 & $\mathrm{AD}$ & $1.72 E-14$ & 1.0000 \\
\hline B & 3.52842 & 0.0005 & $\mathrm{BC}$ & $8.82 E-15$ & 1.0000 \\
\hline C & 2.71392 & 0.0259 & $\mathrm{BD}$ & $5.06 E-15$ & 1.0000 \\
\hline D & 2.18969 & 0.2018 & $\mathrm{CD}$ & $7.89 E-14$ & 1.0000 \\
\hline $\mathrm{AB}$ & 0.00000 & 1.0000 & & & \\
\hline Adj $R$-Squared & \multicolumn{2}{|c|}{0.8795} & Pred $R$-Squared & \multicolumn{2}{|c|}{0.8723} \\
\hline
\end{tabular}

two numbers, the translation will save half of the time. When a new alternative is added or removed, the DMs have no need to deal with it step by step again, but they only need to get the ranking scores by the RS model established before, saving half an hour that the whole procedures usually costs. As a result, the more alternatives are added, the more time will be saved.

\section{Application and Discussion}

It is not easy to make sure that a new proposed method is more reasonable and reliable than the other existing methods in solving different MCDM problems. In order to demonstrate the applicability and potentiality of the method explained in our paper, it is appropriate to make the final decision by applying several MCDM approaches to compare their ranking results for the same problem. The following two illustrative examples are taken to fulfill the task.

4.1. Selection of a Right Partner. As a manufacturer, selecting a right partner is as important as making a high quality product. In this case study, a practical problem with four
TABLE 8: The ranking results.

\begin{tabular}{lccc}
\hline Alternatives & \multicolumn{3}{c}{ Ranking results } \\
& Scores & RSM-TOPSIS-IN & Zhou [41] \\
\hline$S_{1}$ & 0.5826 & 5 & 5 \\
$S_{2}$ & 0.4932 & 4 & 4 \\
$S_{3}$ & 0.3310 & 2 & 3 \\
$S_{4}$ & 0.3745 & 3 & 1 \\
$S_{5}$ & 0.2962 & 1 & 2 \\
\hline
\end{tabular}

performance attributes and five alternative partners is presented [41]. The manufacturer has to choose the most suitable supplier to assure the performance of product. Delivery lead time, product price, product quality, and assortment flexibility are the four factors concerned. We would like to minimize both the delivery lead time and product price while maximizing product quality and assortment flexibility. The author obtained the normalized weight of these criteria as $\omega=(0.36,0.30,0.21,0.13)$ [41] and the performance characteristics of suppliers are stated in Table 6. 
TABLE 9: Decision matrix for road transport technologies.

\begin{tabular}{lcccccc}
\hline Technologies & GHG $(\mathrm{A})$ & PM10 $(\mathrm{B})$ & $\mathrm{NO}_{x}(\mathrm{C})$ & $\mathrm{CO}(\mathrm{D})$ & HCs $(\mathrm{E})$ & Cost $(\mathrm{F})$ \\
\hline HEV & {$[100,400]$} & {$[0.001,0.035]$} & {$[0.10,0.30]$} & {$[0.10,0.5]$} & {$[0.30,1.10]$} & {$[17.55,18.75]$} \\
Av BEV & {$[125,300]$} & {$[0.035,0.135]$} & {$[0.18,0.70]$} & {$[0.10,0.4]$} & {$[0.18,0.60]$} & {$[18.0,19.05]$} \\
Re BEV & {$[25,80]$} & {$[0.005,0.018]$} & {$[0.05,0.15]$} & {$[0.05,0.1]$} & {$[0.05,0.15]$} & {$[18.8,19.4]$} \\
LPG & {$[125,450]$} & {$[0.007,0.035]$} & {$[0.17,0.37]$} & {$[0.50,1.2]$} & {$[0.18,0.65]$} & {$[19.2,22.2]$} \\
CNG & {$[120,420]$} & {$[0.010,0.025]$} & {$[0.05,0.20]$} & {$[0.49,1.0]$} & {$[0.50,1.50]$} & {$[14.8,16.6]$} \\
Petrol & {$[125,500]$} & {$[0.010,0.035]$} & {$[0.10,0.40]$} & {$[0.49,1.0]$} & {$[0.40,1.42]$} & {$[16.8,19.2]$} \\
Diesel & {$[115,430]$} & {$[0.010,0.060]$} & {$[0.25,0.62]$} & {$[0.20,0.5]$} & {$[0.15,0.62]$} & {$[12.5,13.9]$} \\
Bioethanol & {$[80,350]$} & {$[0.023,0.120]$} & {$[0.38,1.20]$} & {$[1.00,3.5]$} & {$[0.19,0.48]$} & {$[14.3,17.0]$} \\
Biodiesel & {$[70,300]$} & {$[0.005,0.070]$} & {$[0.44,1.10]$} & {$[0.2,0.75]$} & {$[0.38,1.20]$} & {$[12.5,13.8]$} \\
\hline Min/max & Min & Min & Min & Min & Min & Min \\
\hline Best & {$[25,80]$} & {$[0.001,0.035]$} & {$[0.05,0.15]$} & {$[0.05,0.1]$} & {$[0.05,0.15]$} & {$[12.5,13.8]$} \\
Worst & {$[125,500]$} & {$[0.035,0.135]$} & {$[0.38,1.20]$} & {$[1.00,3.5]$} & {$[0.50,1.50]$} & {$[19.2,22.2]$} \\
\hline
\end{tabular}

TABLE 10: Two weight sets for assessment of road transport technologies.

\begin{tabular}{lcccccc}
\hline \multirow{2}{*}{ Weight } & \multicolumn{7}{c}{ Emission criteria } \\
& GHG & PM10 & $\mathrm{NO}_{x}$ & CO & HCs & Cost \\
\hline$\omega_{1}$ & 0.16 & 0.16 & 0.16 & 0.16 & 0.16 & 0.2 \\
$\omega_{2}$ & 0.04 & 0.04 & 0.04 & 0.04 & 0.04 & 0.8 \\
\hline
\end{tabular}

In order to deal with this case, $([1.00,1.00],[197,197]$, $[16,16],[0.99,0.99])$ is considered as the ideal alternative. With the proposed method, we are able to generate a RS model expressed in the following equation to evaluate the alternatives:

$$
\begin{aligned}
R= & -0.16128+3.37115 * A+3.52842 * B \\
& +2.71392 * C+2.18969 * D .
\end{aligned}
$$

The ANOVA results are shown in Table 7 specifically, assuring the RS model is available. We obtain the ranking of the alternatives as 5-4-2-3-1, which are almost the same as the results obtained from [41]. The detailed results are tabulated in Table 8.

4.2. Assessment of Road Transport Technologies. It is mentioned that around a quarter of the European Union greenhouse gas emissions are caused by transport, so the paper aims at assessing energy technologies in road transport sector in terms of atmospheric emissions and cost [42]. A TOPSIS method for interval data is proposed and applied to indicate what the most competitive and environmentally friendly transport technology is.

There are nine alternative transports and six performance attributes, including five regulated pollutants and the cost. For the problem, we would like to minimize both regulated pollutants and the cost. The parameters of different modes of cars are given in Table 9.

Using the proposed methodology in our paper, a sixfactor mathematical model is developed. The detailed calculation processes are omitted here. As shown in Table 10, the road transport technologies were assessed in terms of two weight sets. $\omega_{1}$ is the preference under environmental concern and $\omega_{2}$ represents the opinions of consumers, which are all chosen from paper [42]. According to the ANOVA results shown in Table 11, we can get the following two RS models, respectively,

$$
\begin{aligned}
R_{1}= & -0.060525+1.86822 A+1.85112 B+1.91909 C \\
& +2.03517 D+1.94725 E+2.21114 F, \\
R_{2}= & -0.016954+1.46548 A+1.44383 B+1.50011 C \\
& +1.59839 D+1.52191 E+3.48365 F .
\end{aligned}
$$

The comparative results presented in Table 12 show that the ranks are almost the same, which prove the acceptability of the RSM-TOPSIS-IN method in getting the rank of road transport technologies.

\section{Conclusion}

In this paper, a hybrid method called RSM-TOPSIS-IN is proposed to solve MCDM problems with interval data. Both TOPSIS and RSM are applied within the framework. Its main thought distinguished from other methods is that it transforms the interval matrix into a deviation degree matrix, making the matter easy to solve, almost like a normal problem with the exact values. There are two main advantages of the RSM-TOPSIS-IN compared with the other existing methods:

(1) For RSM greatly reduces the cost, time, and amount of calculation steps, when applying the proposed method, DMs can use the obtained RS model to choose and analyse factors and attributes easily, no matter whether they have good numerical capabilities or not. So, simplicity is treated as its first superiority.

(2) If a new alternative is added to or removed from the MCDM problem, the DMs have no need to take the procedures step by step from the beginning, but they can only use the RS model established to get the final 
TABLE 11: The ANOVA results for two RS models.

\begin{tabular}{|c|c|c|c|c|c|}
\hline \multicolumn{3}{|c|}{ RS model with $\omega_{1}$} & \multicolumn{3}{|c|}{ RS model with $\omega_{2}$} \\
\hline Source & Coefficient & $p$ value & Source & Coefficient & $p$ value \\
\hline Intercept & -0.060525 & 0.0000 & Intercept & -0.016954 & 0.0000 \\
\hline A & +1.86822 & $<0.0001$ & A & +1.46548 & $<0.0001$ \\
\hline B & +1.85112 & $<0.0001$ & B & +1.44383 & $<0.0001$ \\
\hline $\mathrm{C}$ & +1.91909 & $<0.0001$ & $\mathrm{C}$ & +1.50011 & $<0.0001$ \\
\hline D & +2.03517 & $<0.0001$ & D & +1.59839 & $<0.0001$ \\
\hline $\mathrm{E}$ & +1.94725 & $<0.0001$ & $\mathbf{E}$ & +1.52191 & $<0.0001$ \\
\hline $\mathbf{F}$ & +2.21114 & $<0.0001$ & $\mathbf{F}$ & +3.48365 & $<0.0001$ \\
\hline $\mathrm{AB}$ & $+1.25 E-14$ & 1.0000 & $\mathrm{AB}$ & $+1.67 E-13$ & 1.0000 \\
\hline $\mathrm{AC}$ & $-1.07 E-13$ & 1.0000 & $\mathrm{AC}$ & $+2.90 E-13$ & 1.0000 \\
\hline $\mathrm{AD}$ & $-1.65 E-14$ & 1.0000 & $\mathrm{AD}$ & $-1.21 E-13$ & 1.0000 \\
\hline $\mathrm{AE}$ & $-8.76 E-14$ & 1.0000 & $\mathrm{AE}$ & $-1.22 E-13$ & 1.0000 \\
\hline $\mathrm{BC}$ & $+2.19 E-14$ & 1.0000 & $\mathrm{BC}$ & $+1.41 E-13$ & 1.0000 \\
\hline $\mathrm{BD}$ & $-8.85 E-15$ & 1.0000 & $\mathrm{BD}$ & $+5.99 E-14$ & 1.0000 \\
\hline $\mathrm{BE}$ & $+6.97 E-14$ & 1.0000 & $\mathrm{BE}$ & $+1.31 E-13$ & 1.0000 \\
\hline $\mathrm{BF}$ & $+6.44 E-14$ & 1.0000 & $\mathrm{BF}$ & $+5.29 E-14$ & 1.0000 \\
\hline $\mathrm{CD}$ & $+4.82 E-15$ & 1.0000 & $\mathrm{CD}$ & $+2.34 E-13$ & 1.0000 \\
\hline $\mathrm{CE}$ & $+3.07 E-14$ & 1.0000 & $\mathrm{CE}$ & $+5.26 E-14$ & 1.0000 \\
\hline $\mathrm{CF}$ & $-6.03 E-14$ & 1.0000 & $\mathrm{CF}$ & $-5.51 E-15$ & 1.0000 \\
\hline $\mathrm{DE}$ & $-2.60 E-14$ & 1.0000 & $\mathrm{DE}$ & $+6.04 E-15$ & 1.0000 \\
\hline DF & $-1.20 E-14$ & 1.0000 & $\mathrm{DF}$ & $-5.07 E-14$ & 1.0000 \\
\hline $\mathrm{EF}$ & $+1.27 E-14$ & 1.0000 & $\mathrm{EF}$ & $-2.60 E-14$ & 1.0000 \\
\hline Adj $R$-Squared & & & Adj $R$-Squared & & \\
\hline Pred $R$-Squared & & & Pred $R$-Squared & & \\
\hline
\end{tabular}

TABLE 12: The ranking results with two weight sets.

\begin{tabular}{lcccccc}
\hline \multirow{2}{*}{ Technologies } & \multicolumn{2}{c}{ Ranking results with $\omega_{1}$} & \multicolumn{2}{c}{ Ranking results with $\omega_{2}$} \\
& Scores & RSM-TOPSIS-IN & Streimikiene et al. [42] & Scores & RSM-TOPSIS-IN & Streimikiene et al. [42] \\
\hline HEV & 0.5678 & 3 & 2 & 0.6270 & 6 & 5 \\
Av BEV & 0.6970 & 8 & 8 & 0.6352 & 7 & 8 \\
Re BEV & 0.3193 & 1 & 1 & 0.6473 & 8 & 7 \\
LPG & 0.6830 & 6 & 4 & 0.6862 & 9 & 3 \\
CNG & 0.5730 & 4 & 5 & 0.5745 & 3 & 6 \\
Petrol & 0.6945 & 7 & 6 & 0.6259 & 5 & 1 \\
Diesel & 0.4793 & 2 & 3 & 0.5210 & 1 & 4 \\
Bioethanol & 0.9303 & 9 & 9 & 0.5772 & 4 & 2 \\
Biodiesel & 0.6202 & 5 & 7 & 0.5225 & & 2 \\
\hline
\end{tabular}

results, reducing both time and effort. This makes efficiency the other advantage.

Three examples illustrated later verify the capability of this method, indicating it is simple to comprehend and easy to implement. Due to its convenient and practicability, it is easy to draw a conclusion that the RSM-TOPSIS-IN method is suitable for solving MCDM problems with interval numbers. The same hybrid idea can also be applied to other methodologies, which may become a new direction of our future research.

\section{Conflict of Interests}

The authors declare that there is no conflict of interests regarding the publication of this paper.

\section{Acknowledgments}

The authors are grateful to the editor and the anonymous referees for their insightful and constructive comments and suggestions, which have been very helpful in improving this paper. This research was supported by the National Natural 
Science Foundation of China under Grant no. 51375389; Fundamental Research Funds for the Central Universities under Grant no. 3102014JCQ01007; and Civil Aviation Joint Fund under Grant no. U1333133.

\section{References}

[1] A. Afshari, M. Mojahed, and R. M. Yusuff, "Simple additive weighting approach to personnel selection problem," International Journal of Innovation, Management and Technology, vol. 1, pp. 511-515, 2010.

[2] M. F. Chen and G. H. Tzeng, "Combining grey relation and TOPSIS concepts for selecting an expatriate host country," Mathematical and Computer Modelling, vol. 40, no. 13, pp. 14731490, 2004.

[3] T. L. Saaty, "Decision making with the analytic hierarchy process," International Journal of Services Sciences, vol. 1, pp. 8398, 2008.

[4] P. Wang, P. Meng, J.-Y. Zhai, and Z.-Q. Zhu, "A hybrid method using experiment design and grey relational analysis for multiple criteria decision making problems," Knowledge-Based Systems, vol. 53, pp. 100-107, 2013.

[5] W. K. M. Brauers and E. K. Zavadskas, "The MOORA method and its application to privatization in a transition economy," Control and Cybernetics, vol. 35, no. 2, pp. 445-469, 2006.

[6] T. Yang and C.-C. Hung, "Multiple-attribute decision making methods for plant layout design problem," Robotics and Computer-Integrated Manufacturing, vol. 23, no. 1, pp. 126-137, 2007.

[7] M. Ehrgott, K. Klamroth, and C. Schwehm, "An MCDM approach to portfolio optimization," European Journal of Operational Research, vol. 155, no. 3, pp. 752-770, 2004.

[8] L. Anojkumar, M. Ilangkumaran, and V. Sasirekha, "Comparative analysis of MCDM methods for pipe material selection in sugar industry," Expert Systems with Applications, vol. 41, no. 6, pp. 2964-2980, 2014.

[9] J. Kangas, A. Kangas, P. Leskinen, and J. Pykäläinen, "MCDM methods in strategic planning of forestry on state-owned lands in finland: applications and experiences," Journal of MultiCriteria Decision Analysis, vol. 10, pp. 257-271, 2001.

[10] T.-C. Wang and T.-H. Chang, "Application of TOPSIS in evaluating initial training aircraft under a fuzzy environment," Expert Systems with Applications, vol. 33, no. 4, pp. 870-880, 2007.

[11] C.-T. Chen, "Extensions of the TOPSIS for group decisionmaking under fuzzy environment," Fuzzy Sets and Systems, vol. 114, no. 1, pp. 1-9, 2000.

[12] M. A. Abo-Sinna and A. H. Amer, "Extensions of TOPSIS for multi-objective large-scale nonlinear programming problems," Applied Mathematics and Computation, vol. 162, no. 1, pp. 243256, 2005.

[13] Y. T. İç, "An experimental design approach using TOPSIS method for the selection of computer-integrated manufacturing technologies," Robotics and Computer-Integrated Manufacturing, vol. 28, no. 2, pp. 245-256, 2012.

[14] G. R. Jahanshahloo, F. H. Lotfi, and M. Izadikhah, "An algorithmic method to extend TOPSIS for decision-making problems with interval data," Applied Mathematics and Computation, vol. 175, no. 2, pp. 1375-1384, 2006.

[15] R. E. Bellman and L. A. Zadeh, "Decision-making in a fuzzy environment," Management Science, vol. 17, no. 4, pp. 141-164, 1970.
[16] F. E. Boran, S. Genç, M. Kurt, and D. Akay, "A multi-criteria intuitionistic fuzzy group decision making for supplier selection with TOPSIS method," Expert Systems with Applications, vol. 36, no. 8, pp. 11363-11368, 2009.

[17] A. H. I. Lee, W.-C. Chen, and C.-J. Chang, "A fuzzy AHP and BSC approach for evaluating performance of IT department in the manufacturing industry in Taiwan," Expert Systems with Applications, vol. 34, no. 1, pp. 96-107, 2008.

[18] A. Peng and Z. Wang, "GRA-based TOPSIS decision-making approach to supplier selection with interval number," in Proceedings of the Chinese Control and Decision Conference (CCDC '11), pp. 1742-1747, May 2011.

[19] S. Chen, C. Hwang, and F. Hwang, Fuzzy Multiple Attribute Decision Making, vol. 375 of Lecture Notes in Economics and Mathematical Systems, Springer, Berlin, Germany, 1992.

[20] C. Carlsson and R. Fullér, "Fuzzy multiple criteria decision making: recent developments," Fuzzy Sets and Systems, vol. 78, no. 2, pp. 139-153, 1996.

[21] E. Kaucher, "Interval analysis in the extended interval space IR," in Fundamentals of Numerical Computation, Computer Oriented Numerical Analysis, pp. 33-49, Springer, Berlin, Germany, 1980.

[22] V. Y. C. Chen, H.-P. Lien, C.-H. Liu, J. J. H. Liou, G.-H. Tzeng, and L.-S. Yang, "Fuzzy MCDM approach for selecting the best environment-watershed plan," Applied Soft Computing, vol. 11, no. 1, pp. 265-275, 2011.

[23] C. Jiang, X. Han, F. J. Guan, and Y. H. Li, "An uncertain structural optimization method based on nonlinear interval number programming and interval analysis method," Engineering Structures, vol. 29, no. 11, pp. 3168-3177, 2007.

[24] X. Zhang and P. Liu, "Method for multiple attribute decisionmaking under risk with interval numbers," International Journal of Fuzzy Systems, vol. 12, no. 3, pp. 237-242, 2010.

[25] G.-H. Tzeng and J.-J. Huang, Multiple Attribute Decision Making: Methods and Applications, CRC Press, New York, NY, USA, 2011.

[26] C. Hwang and K. Yoon, Multiple Attribute Decision Making: Methods and Application, Springer, New York, NY, USA, 1981.

[27] K. Yoon, "A reconciliation among discrete compromise solutions," Journal of the Operational Research Society, vol. 38, no. 3, pp. 277-286, 1987.

[28] C.-L. Hwang, Y.-J. Lai, and T.-Y. Liu, "A new approach for multiple objective decision making," Computers \& Operations Research, vol. 20, no. 8, pp. 889-899, 1993.

[29] P. Karande and S. Chakraborty, "Application of multi-objective optimization on the basis of ratio analysis (MOORA) method for materials selection," Materials \& Design, vol. 37, pp. 317-324, 2012.

[30] K. P. Yoon and C.-L. Hwang, Multiple Attribute Decision Making: An Introduction, Sage, Thousand Oaks, Calif, USA, 1995.

[31] M. M. Deza and E. Deza, Encyclopedia of Distances, Springer, New York, NY, USA, 2009.

[32] M. F. Aly, H. A. Attia, and A. M. Mohammed, "Integrated fuzzy (GMM)-TOPSIS model for best design concept and material selection process," International Journal of Innovative Research in Science, Engineering and Technology, vol. 2, pp. 6464-6486, 2013.

[33] X. Zhang and Z. Xu, "Extension of TOPSIS to multiple criteria decision making with pythagorean fuzzy sets," International Journal of Intelligent Systems, vol. 29, pp. 1061-1078, 2014. 
[34] J. R. San Cristóbal, Multi Criteria Analysis in the Renewable Energy Industry, Springer, Berlin, Germany, 2012.

[35] R. E. Kirk, Experimental Design, John Wiley \& Sons, New York, NY, USA, 1982.

[36] M. A. Bezerra, R. E. Santelli, E. P. Oliveira, L. S. Villar, and L. A. Escaleira, "Response surface methodology (RSM) as a tool for optimization in analytical chemistry," Talanta, vol. 76, no. 5, pp. 965-977, 2008.

[37] A. Kannan, K. Esakkiraja, and M. Nataraj, "Modeling and analysis for cutting temperature in turning of aluminium 6063 using response surface methodology," IOSR Journal of Mechanical and Civil Engineering, vol. 9, pp. 59-64, 2013.

[38] Y. Lian and M.-S. Liou, "Multiobjective optimization using coupled response surface model and evolutionary algorithm," AIAA Journal, vol. 43, no. 6, pp. 1316-1325, 2005.

[39] F.-X. Zhu and H.-Y. Chen, "A method of entropy for obtaining the attribute weights of interval numbers decision-making matrix," Journal of Anhui University (Natural Science Edition), vol. 5, pp. 4-6, 2006.

[40] F.-X. Zhu, "A new method based on deviation degree for priority of decision-making matrix," Journal of Hefei University, vol. 15, pp. 1-4, 2005.

[41] C. Zhou, "Approach to incidence decision making model of multi-attribute interval number on supplier selection," in Proceedings of the International Conference on Intelligent Control and Information Processing (ICICIP '10), pp. 78-82, IEEE, August 2010.

[42] D. Streimikiene, T. Baležentis, and L. Baležentiene, "Comparative assessment of road transport technologies," Renewable and Sustainable Energy Reviews, vol. 20, pp. 611-618, 2013. 


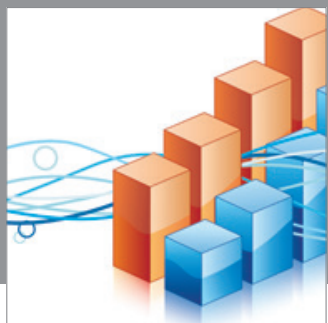

Advances in

Operations Research

mansans

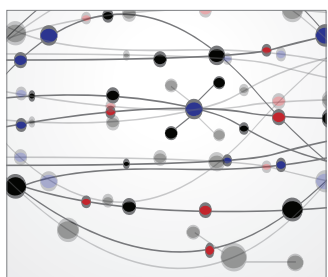

The Scientific World Journal
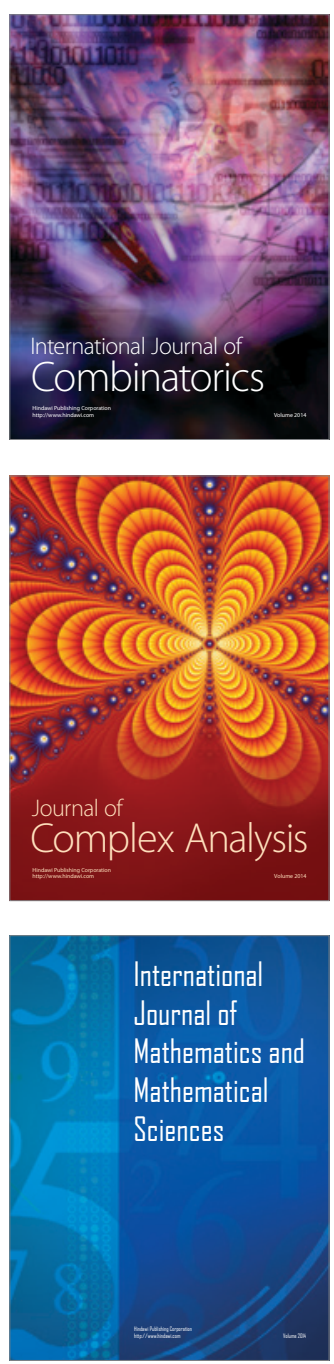
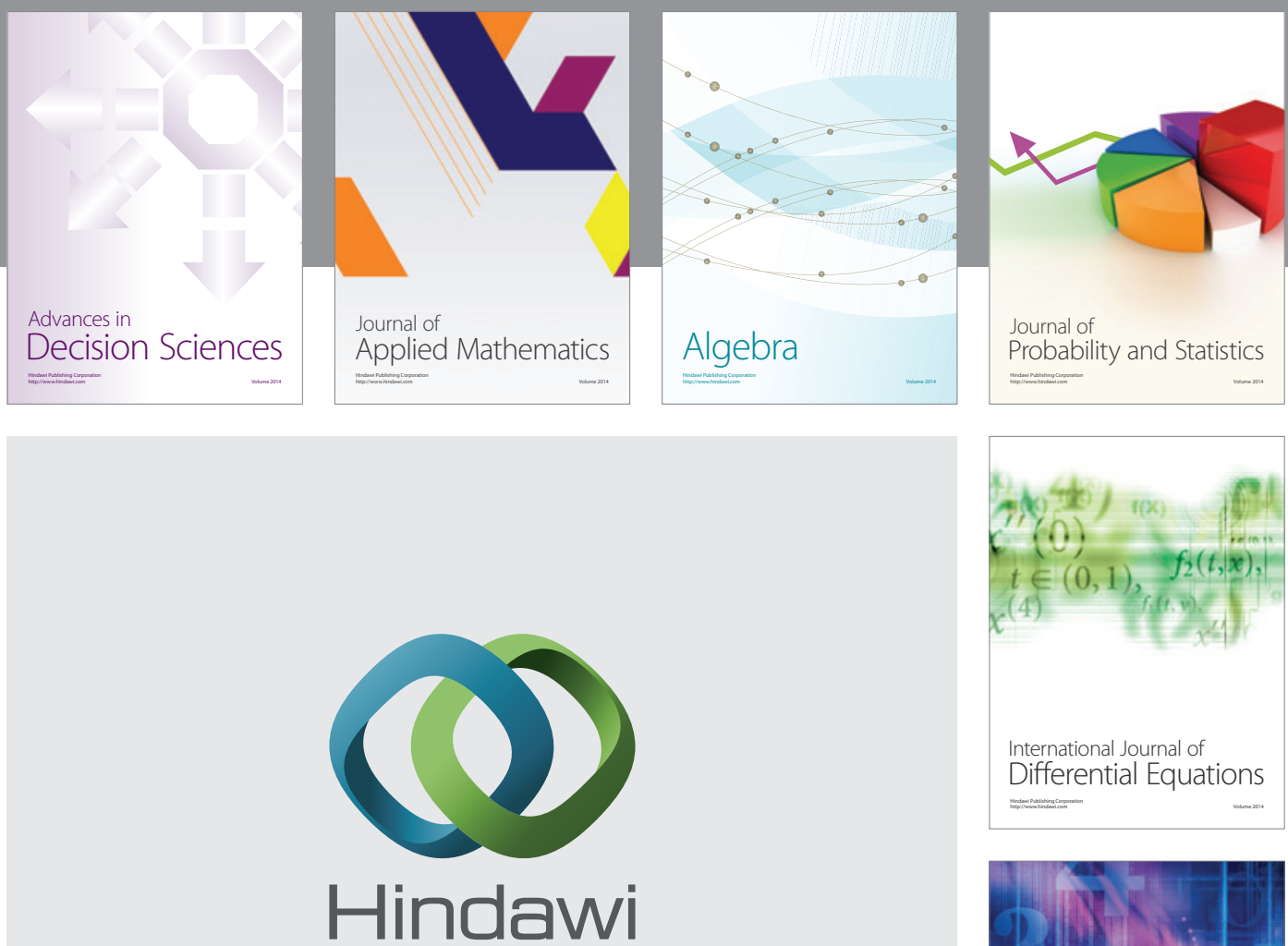

Submit your manuscripts at http://www.hindawi.com
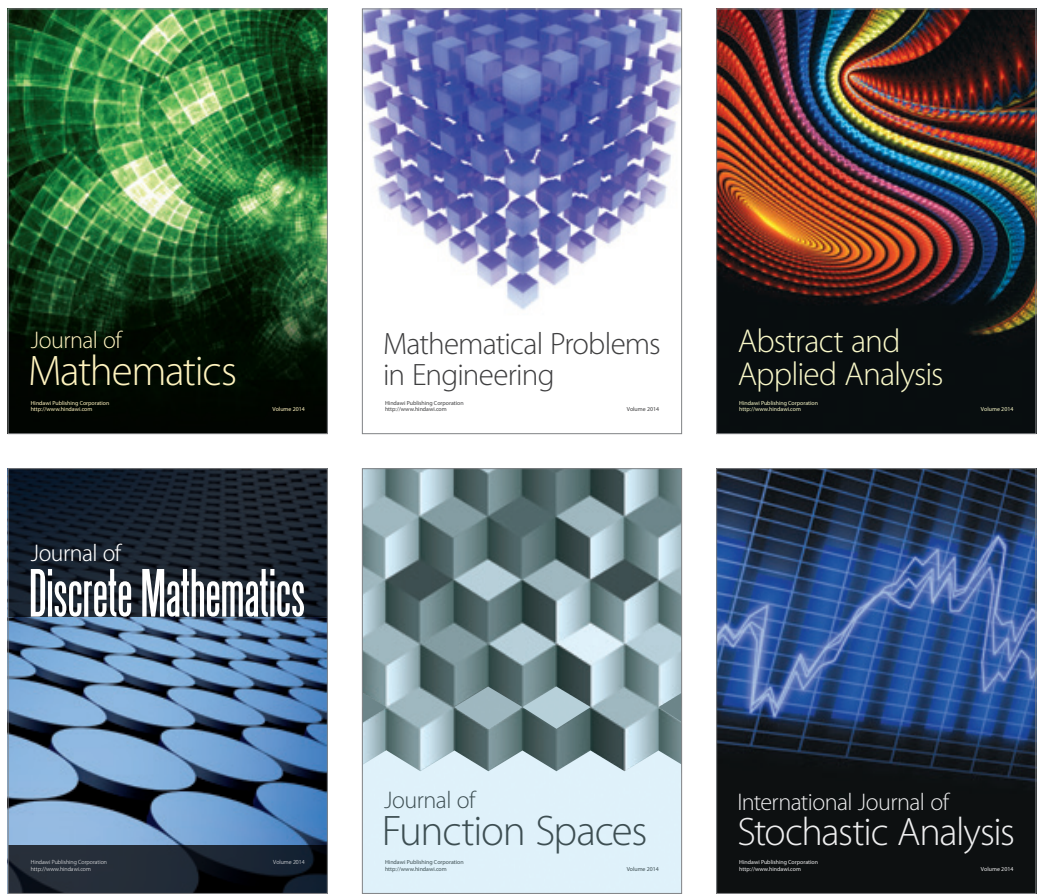

Journal of

Function Spaces

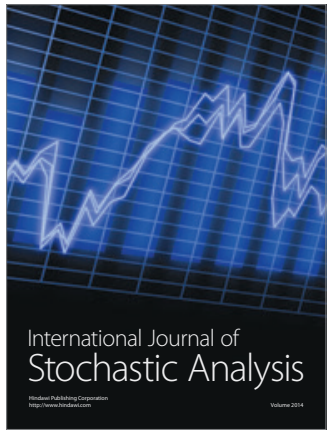

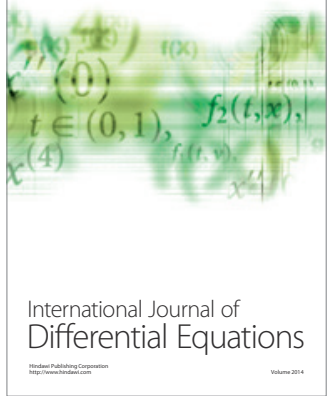
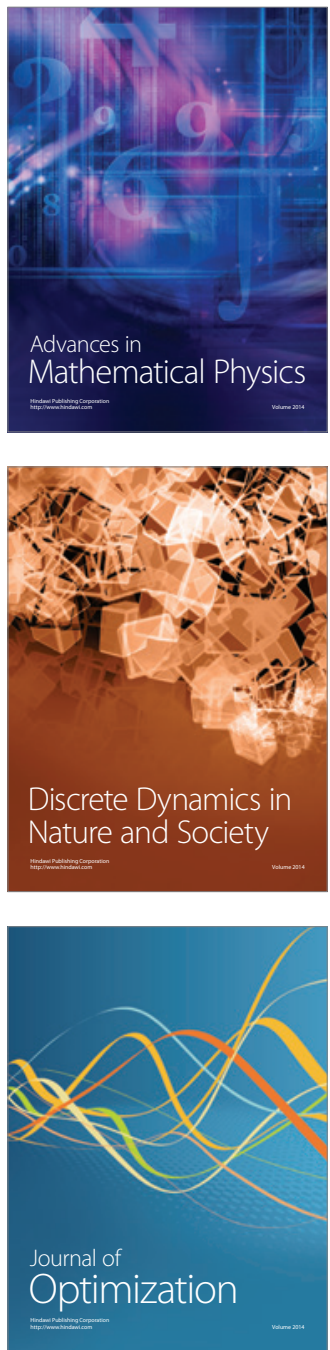